\title{
Cancer patient perceptions on the ethical and legal issues related to biobanking
}

\author{
Zubin Master ${ }^{1,2}$, Jaime O Claudio ${ }^{3}$, Christen Rachul ${ }^{2}$, Jean CY Wang ${ }^{4}$, Mark D Minden $^{5}$ and Timothy Caulfield ${ }^{6^{*}}$
}

\begin{abstract}
Background: Understanding the perception of patients on research ethics issues related to biobanking is important to enrich ethical discourse and help inform policy.

Methods: We examined the views of leukemia patients undergoing treatment in clinics located in the Princess Margaret Hospital in Toronto, Ontario, Canada. An initial written survey was provided to 100 patients (64.1\% response rate) followed by a follow-up survey (62.5\% response rate) covering the topics of informed consent, withdrawal, anonymity, incidental findings and the return of results, ownership, and trust.
\end{abstract}

Results: The majority (59.6\%) preferred one-time consent, 30.3\% desired a tiered consent approach that provides multiple options, and $10.1 \%$ preferred re-consent for future research. When asked different questions on re-consent, most (58\%) reported that re-consent was a waste of time and money, but 51.7\% indicated they would feel respected and involved if asked to re-consent. The majority of patients (62.2\%) stated they had a right to withdraw their consent, but many changed their mind in the follow-up survey explaining that they should not have the right to withdraw consent. Nearly all of the patients (98\%) desired being informed of incidental health findings and explained that the information was useful. Of these, $67.3 \%$ of patients preferred that researchers inform them and their doctors of the results. The majority of patients (62.2\%) stated that the research institution owns the samples whereas $19.4 \%$ stated that the participants owned their samples. Patients had a great deal of trust in doctors, hospitals and government-funded university researchers, moderate levels of trust for provincial governments and industry-funded university researchers, and low levels of trust towards industry and insurance companies.

Conclusions: Many cancer patients surveyed preferred a one-time consent although others desired some form of control. The majority of participants wanted a continuing right to withdraw consent and nearly all wanted to be informed of incidental findings related to their health. Patients had a great deal of trust in their medical professionals and publically-funded researchers as opposed to profit-based industries and insurance companies.

Keywords: Biobank, Tissue repository, Cancer patient perspectives, Consent, Withdrawal, Anonymity, Incidental findings, Return of results, Ownership, Trust

\section{Background}

The large-scale collection of biological materials along with health and demographic information has become an important research tool in many areas of the biomedical sciences. Biobanking involves the collection and longterm storage of biological materials (e.g., blood, DNA, urine, cells, etc.) and health information. Biobanks are valuable research platforms that allow for future research

\footnotetext{
* Correspondence: tcaulfld@law.ualberta.ca

${ }^{6}$ Health Law and Science Policy Group, Rm 462 Faculty of Law and School of Public Health, Law Centre, University of Alberta, 89 Avenue and 111 Street, Edmonton, AB T6G 2H5, Canada

Full list of author information is available at the end of the article
}

studies on stored samples. Investigators can, for example, analyze data derived from biological samples (i.e., presence of a gene sequence), and correlate that analysis with other data (e.g., health information or demographics) to identify statistical relationships. Biobanking can also allow the sharing of biological samples with other researchers. Large-scale biorepositories have been viewed as necessary to improve our understanding of disease and to develop new diagnostic and treatment modalities. Substantial investments have been made at local, state, and national levels to create biobanks in jurisdictions such as the United Kingdom, United States, 
Sweden, Iceland, Canada, Denmark, Finland, and several other countries [1-4].

Biobanks have generated a range of ethical and legal challenges related to privacy, informed consent [5], control and ownership [6,7], withdrawal of samples and consent [8], commercialization, return of results and incidental findings [9], and research governance. Indeed, these issues have generated much policy debate and have already resulted in several public controversies regarding informed consent [10-12], commercialization [13], and control, and ownership [14-16]. Gaining a greater understanding of the perspectives of different stakeholders, including patients who provide biological samples and health information to biobanks can offer insight into the nature and drivers of these ethical controversies, inform policy development, and assist in public engagement.

While there are many studies evaluating public and patient perspectives on biobanking, only a few capture the views of Canadians [17-21] and even fewer capture those of patients. Because patients may be more invested in research and have different expectations than the general public [22], gaining an understanding of the views of this population will help to provide insight into the breadth of perspectives relevant to biobanking. In this study, we performed a survey of leukemia patients receiving treatment at Princess Margaret Hospital's Hematology Oncology Clinic on several issues related to biobanking, including informed consent, withdrawal, anonymity, return of results, ownership, privacy, and trust. Patients were provided with written surveys during an initial visit and the same survey was provided six months later in order to determine whether their views had changed on various ethical and legal issues regarding biorepository research. A six month period provided sufficient time for patients to receive treatment and interact with physicians and clinic staff, which may have influenced their views about biobanking and participation in research.

\section{Methods}

\section{Research setting}

As part of a large research study designed to understand the perspectives of different Canadian stakeholder groups on biobanking, we recruited 100 patients from June 22 to October 12, 2011 who received treatment for leukemia at six different hematology-oncology clinics at Princess Margaret Hospital in Toronto, Ontario, Canada. Patients were receiving chemotherapy or other treatment for leukemia and some were in remission. As two of the authors (MM and JW) are co-directors of the Princess Margaret Hospital Hematologic Malignancy Tissue Bank, patients participating in this bank were invited to participate in our survey as a convenience sample. All patients were 16 years of age or older, and the majority lived in the Greater Toronto Area and surrounding municipalities although a few lived in Northern Ontario. The Greater Toronto Area has a multicultural and multiethnic population.

Patients were informed by their attending hematologist that a researcher (JC) might approach them to participate in the biobank survey. A short consent form explaining the study was provided along with a verbal explanation. After consent was obtained, patients were left with the survey to complete and a copy of the informed consent form. This project received research ethics approval from the University of Alberta Research Ethics Board (MS2_Pro00021037) and the University Health Network Research Ethics Board (11-0380-BE) prior to patient enrolment.

A total of 100 out of 156 patients participated by completing the initial survey providing a response rate of $64.1 \%$. Patients were given ample time to fill out the survey and most were completed while the patient was still in the clinic; two patients completed the questionnaire at home and returned it by mail. Seventy eight patients that participated in the survey had already consented for their samples to be deposited in the Princess Margaret Hospital Hematologic Malignancy Tissue Bank (REB 01-0573-C) at the time the survey was given to them. At the time of recruitment for the initial survey, patients were also asked if they would agree to participate in a follow-up survey six months later. Of the 72 patients who provided consent to complete a follow-up survey, only 45 returned a completed follow-up survey giving a response rate of $62.5 \%$. Of the 100 patients participating in the initial survey, 60 were male and 40 were female. For the follow-up survey, 27 males and 18 females participated thereby maintaining the $60-40$ male to female ratio in both the initial and follow-up surveys.

\section{Survey design and analysis}

This survey is part of a larger initiative designed to understand and compare the opinions of different stakeholders, including the public [22], on a breath of research ethics topics related to biobanking. Survey questions were designed based on (1) a systematic search of the published academic literature in order to identify the ethical and legal challenges associated with biobanking [23], and (2) an analysis of specific surveys on the ethical and legal issues associated with biobanking. Interviewers at the University of Alberta's Population Research Laboratory pre-tested the survey with 20 Albertans from May 9-11, 2011 [22].

This study aimed to explore the perspectives of patients undergoing leukemia treatment where most of the patients participated in a local biobanking project. The survey had nine questions containing multiple parts with 
either fixed choices or 4 or 5-point Likert scale responses. A copy of the questionnaire is available online as Additional file 1.

Recruitment of patients and the collection of responses for the initial and follow-up surveys were done in Toronto, and subsequent analysis was performed by researchers affiliated with the University of Alberta. No patient identifying information was sent to researchers at the University of Alberta. Comparisons between the initial and follow-up surveys were done only for those participants that completed both surveys.

\section{Statistical analysis}

Data were tabulated and analyzed using IBM SPSS 19 for Windows. To determine statistical relevance, Pearson's Chi-Square $\left(\chi^{2}\right)$ Tests were performed as we aimed to determine whether our observed sample of nominal scale data conformed to an expected distribution. Statistical significance was determined where the null-hypothesis (no difference in categories) was rejected with a $p<0.05$. In order to maintain statistical accuracy, responses where participants chose more than one response or failed to respond were not included in the final count when performing statistical analysis.

As only 45 of the initial 100 patients completed the follow-up survey we wanted to determine whether there was a potential bias due to non-response. We compared responses between those who completed the follow-up survey with those who did not. Chi-Square tests did not yield any significant differences in the responses of these two groups, and therefore, we do not suspect a response bias.

\section{Results}

Consent

We first set out to determine patients' preferences on informed consent for biobanking, asking them to choose one of three consent models: (a) specific/re-consent, (b) one-time general consent, and (c) tiered consent. From our initial set of survey responses, we found that out of 89 patients that responded, $59.6 \%$ preferred onetime consent while $30.3 \%$ preferred a tiered approach, and $10.1 \%$ preferred to re-consent for every future research project $\left(X^{2}=32.989, \mathrm{df}=2, p<0.001\right)$ (Table 1$)$. Of the 45 participants that completed both initial and follow-up surveys, a significant number of responses changed $(n=20)$, such that slightly more participants preferred one-time consent and fewer preferred tiered consent $\left(x^{2}=47.356, \mathrm{df}=3, p<0.001\right)$ (Table 1$)$.

To further understand patient views on informed consent, we asked participants about their views specific to re-consenting. Approximately 58\% of patients agreed or strongly agreed that it was a waste of time and money while $36.6 \%$ disagreed or strongly disagreed $\left(x^{2}=22.108\right.$, $\mathrm{df}=4, p<0.001$ ) (Figure 1). Patients had a range of opinions when asked whether they would feel bothered by re-consenting with differences not being statistically significant $\left(\chi^{2}=5.976, \mathrm{df}=4, p=0.201\right)$. When patients were asked if they would have more control if asked to re-consent, about $21.4 \%$ disagreed, 30\% agreed, and $34.5 \%$ were indifferent (Figure 1). Only $7.1 \%$ either strongly agreed or strongly disagreed indicating that only a few patients had strong views on the topic of control $\left(x^{2}=26.833, \mathrm{df}=4, p<0.001\right)$. Approximately $40 \%$ of patients reported that they agreed or strongly agreed on having greater trust in a study if they were allowed to re-consent, $33.7 \%$ were indifferent, while $26.7 \%$ disagreed or strongly disagreed $\left(\chi^{2}=18.651, \mathrm{df}=4\right.$, $p=0.001$ ). Lastly, when we asked patients if they would feel respected and involved if they were asked to reconsent, a significant $51.7 \%$ agreed or strongly agreed while $18.4 \%$ disagreed or strongly disagreed $\left(x^{2}=27.540, \mathrm{df}=4\right.$, $p<0.001$ ) (Figure 1). Follow-up survey responses showed that more patients had less trust in the study $\left(X^{2}=44.260\right.$, $\mathrm{df}=25, p=0.01)$ and fewer felt respected and involved $\left(x^{2}=41.127, \mathrm{df}=25, p=0.022\right)$ than what was reported by participants in the initial survey (data not shown).

\section{Withdrawal}

On the topic of withdrawing consent, we found that $62.6 \%$ of patients wanted to have the right to withdraw their sample and health information from a biobank $\left(\mathrm{X}^{2}=6.313, \mathrm{df}=1, p=0.012, \mathrm{n}=99\right)$ (Table 2$)$. A particularly

Table 1 Patient preferences of different informed consent approaches for biobanking

\begin{tabular}{|c|c|c|c|c|c|c|}
\hline \multirow[t]{2}{*}{ Type of consent } & \multicolumn{2}{|c|}{$\begin{array}{l}\text { Initial survey } \\
\text { responses }\end{array}$} & \multicolumn{4}{|c|}{ Follow-up survey responses } \\
\hline & $(n=89)$ & $\%$ & $\begin{array}{l}\text { Initial } \\
(n=43)\end{array}$ & $\%$ & $\begin{array}{l}\text { Follow-up } \\
(n=43)\end{array}$ & $\%$ \\
\hline $\begin{array}{l}\text { Re-consent: The researchers should ask you for your permission to use them every time } \\
\text { they would like to do a new study }\end{array}$ & 9 & 10.1 & 2 & 9.3 & 5 & 11.6 \\
\hline $\begin{array}{l}\text { One time consent: The researchers should only ask for your permission to use them once, } \\
\text { thus allowing researchers to use them for as many studies as they would like }\end{array}$ & 53 & 59.6 & 29 & 67.4 & 31 & 72.1 \\
\hline $\begin{array}{l}\text { Tiered consent: The researchers should provide you with options regarding the types of } \\
\text { studies your stored samples and health information could and could not be used in }\end{array}$ & 27 & 30.3 & 10 & 23.3 & 7 & 16.3 \\
\hline
\end{tabular}

Due to rounding, totals may not equal $100 \%$. 


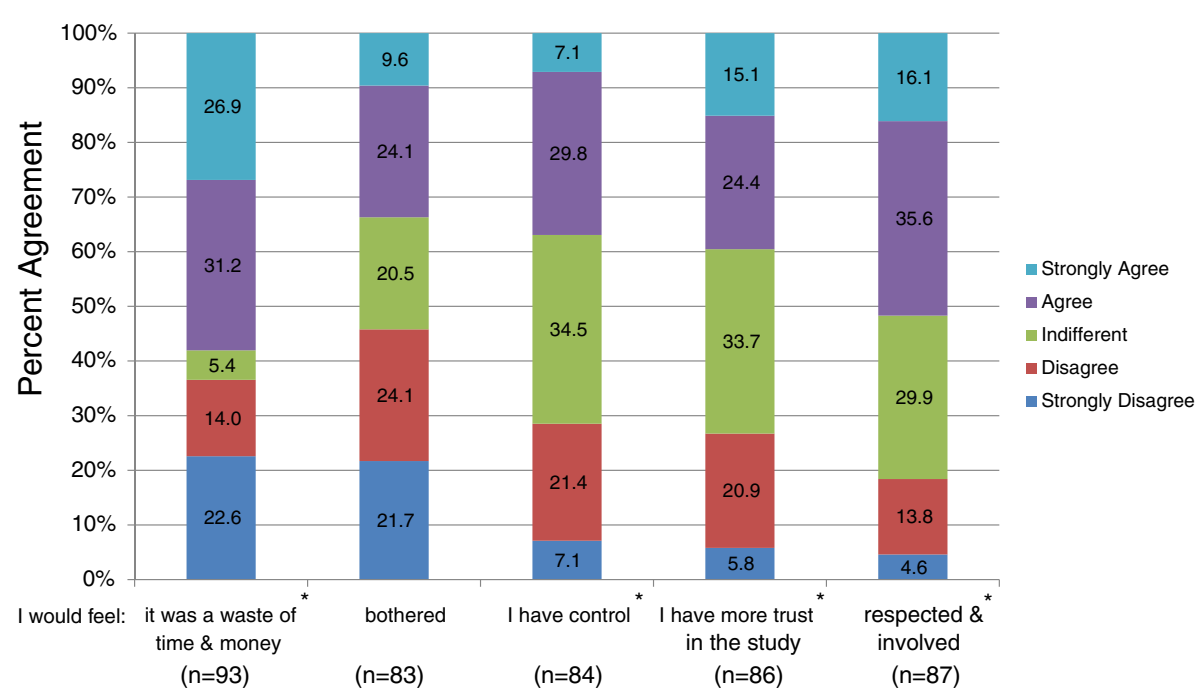

Figure 1 Patient perspectives on re-consenting for each new study. Likert scale responses of leukemia patients' perceptions on re-consent was quantified. Question: How would you feel if you had to give permission to use your stored biological sample and health information before each new study? (a) I would feel it was a waste of time and money. (b) I would feel bothered. (c) I would feel I have control. (d) I would feel more trust in the study. (e) I would feel respected and involved. * indicates the questions to which patient responses were statistically significant. Due to rounding, totals may not equal $100 \%$.

interesting finding was that $77.3 \%$ of participants changed their response on withdrawal in the follow-up survey (data not shown). This resulted in a significant proportion of patients moving from wanting to have a right to withdraw to deciding that they should not have a right to withdraw consent for future medical research $\left(\chi^{2}=12.259, \mathrm{df}=4\right.$, $p=0.016)$ (Table 2).

\section{Anonymity}

In order to understand cancer patient perspectives on anonymity, we asked patients whether it was more important to have a sample anonymized (described as no way to trace back to donor) or de-identified (described as researchers do not readily know who the sample belongs to, but there is a way to trace it back to the participant). The results were split: $54.6 \%$ of participants desired samples to be anonymized while $45.4 \%$ desired de-identification of samples; this difference was not statistically significant $\left(\chi^{2}=0.835, \mathrm{df}=1, p=0.361, \mathrm{n}=97\right)$. The follow-up survey showed an increase in the number of participants desiring samples to be anonymized instead of de-identified, but these changes were not statistically significant $\left(\mathrm{x}^{2}=3.85, \mathrm{df}=2, p=0.146\right)$.

\section{Return of results}

Patients were presented with a scenario in which researchers discovered incidental findings related to their health, but unrelated to the initial study. They were asked how researchers should handle this situation: do nothing, inform them, inform their doctor, or inform both them and their doctor. Of the 98 participants that provided responses, only $2 \%$ indicated that nothing should be done and $8.2 \%$ preferred to know themselves (Table 3). Many patients (22.4\%) preferred instead that researchers should notify their physician while most of the patients $(67.3 \%)$ preferred that researchers should inform both them and their doctor $\left(x^{2}=102.327, \mathrm{df}=3\right.$, $p<0.001)$.

\section{Public health surveillance}

We asked participants how they would feel if a policy was put in place that allowed a public health worker to analyze their health information and mail information to them related to potential chronic health risks (e.g., an increased risk of diabetes). We found that the majority $(82.9 \%)$ agreed or strongly agreed that the information would be useful $\left(x^{2}=79.298, \mathrm{df}=4, p<0.001\right)$ while only

Table 2 Patient perspectives on the right to withdraw informed consent

\begin{tabular}{|c|c|c|c|c|c|c|}
\hline \multirow{2}{*}{$\begin{array}{l}\text { Do you think you should have } \\
\text { the right to withdraw: }\end{array}$} & \multicolumn{2}{|c|}{ Initial survey responses } & \multicolumn{4}{|c|}{ Follow-up survey responses } \\
\hline & $(n=99)$ & $\%$ & Initial $(n=44)$ & $\%$ & Follow-up $(n=44)$ & $\%$ \\
\hline Yes & 62 & 62.6 & 27 & 61.4 & 23 & 52.3 \\
\hline No & 37 & 37.4 & 17 & 38.6 & 21 & 47.7 \\
\hline
\end{tabular}

Due to rounding, totals may not equal $100 \%$. 
Table 3 Patient preferences on the return of incidental findings

\begin{tabular}{lcc}
\hline What do you think researchers & \multicolumn{2}{c}{ Initial survey responses } \\
\cline { 2 - 3 } $\begin{array}{l}\text { should do upon discovering } \\
\text { health information? }\end{array}$ & $\mathbf{( n = 9 8 )}$ & $\%$ \\
\hline Nothing & 2 & 2.0 \\
Tell me & 22 & 8.2 \\
Tell my doctor & 66 & 22.4 \\
Tell both myself and my doctor & & 67.3 \\
\hline
\end{tabular}

Due to rounding, totals may not equal $100 \%$.

$20.5 \%$ agreed or strongly agreed it would be a waste of time and a poor use of resources $\left(x^{2}=21.880, \mathrm{df}=4\right.$, $p<0.001$ ) (Figure 2). More participants $(50.6 \%)$ disagreed or strongly disagreed that their privacy would be invaded $\left(x^{2}=16.578, \mathrm{df}=4, p=0.002\right)$ (Figure 2). A significant number of responses changed in the followup survey for two areas. Half of the 44 participants who completed the follow-up survey changed their mind resulting in about a $10 \%$ decrease of participants who agreed or strongly agreed that the information would be useful $\left(x^{2}=51.075, \mathrm{df}=25, p=0.002\right)$. Additionally, in the follow-up survey, the majority of participants changed their minds resulting in 10\% greater response of disagreeing or strongly disagreeing that returning health results was a waste of time and a poor use of resources $\left(x^{2}=61.140, \mathrm{df}=25, p<0.001\right)$.

\section{Ownership and decision-making}

To assess perspectives on ownership, we asked participants who they believe owned banked samples: the participant, the researcher conducting the research, the institution where the research is being conducted, or the funder(s) of the research. Of the 98 responses received in the initial survey, the majority of participants $(62.2 \%)$ stated that the research institution owned the samples. But a significant minority reported that research participants $(19.4 \%)$ or the researcher $(16.3 \%)$ owned the samples. Only $2 \%$ explained that the funder owned the samples $\left(x^{2}=79.224, \mathrm{df}=3, p<0.001\right)$.

On a similar line of questioning, we asked patients if they had a continuing right to decide what is done with their samples. Of the 95 responses collected in the initial survey, $55.8 \%$ indicated they should have the right to decide what is done with their samples $\left(x^{2}=1.274, \mathrm{df}=15\right.$, $p<0.259$ ).

\section{Trust}

The final question of the survey asked patients about their levels of trust in different actors and their organizations in regards to the care and use of their confidential health information. Patients were able to indicate whether they trusted different individuals or organizations "A great deal," "Somewhat," or "Not at all," or they were able to respond as "Don't know." Patients had a great deal of trust in doctors $(71.3 \%)\left(x^{2}=73.196\right.$, $\mathrm{df}=2, p<0.001)$, hospitals $(63.4 \%)\left(x^{2}=55.473, \mathrm{df}=2\right.$, $p<0.001$ ), university researchers funded by government (40.4\%) $\left(x^{2}=37.640, \mathrm{df}=2, p<0.001\right)$, and disease based foundations $\quad(31.2 \%) \quad\left(x^{2}=43.103, \quad \mathrm{df}=2, \quad p<0.001\right)$ (Figure 3). Patients somewhat trusted the government in their province $(56.8 \%)\left(x^{2}=37.640, \mathrm{df}=2, p<0.001\right)$, data collection agencies, e.g., Statistics Canada or the

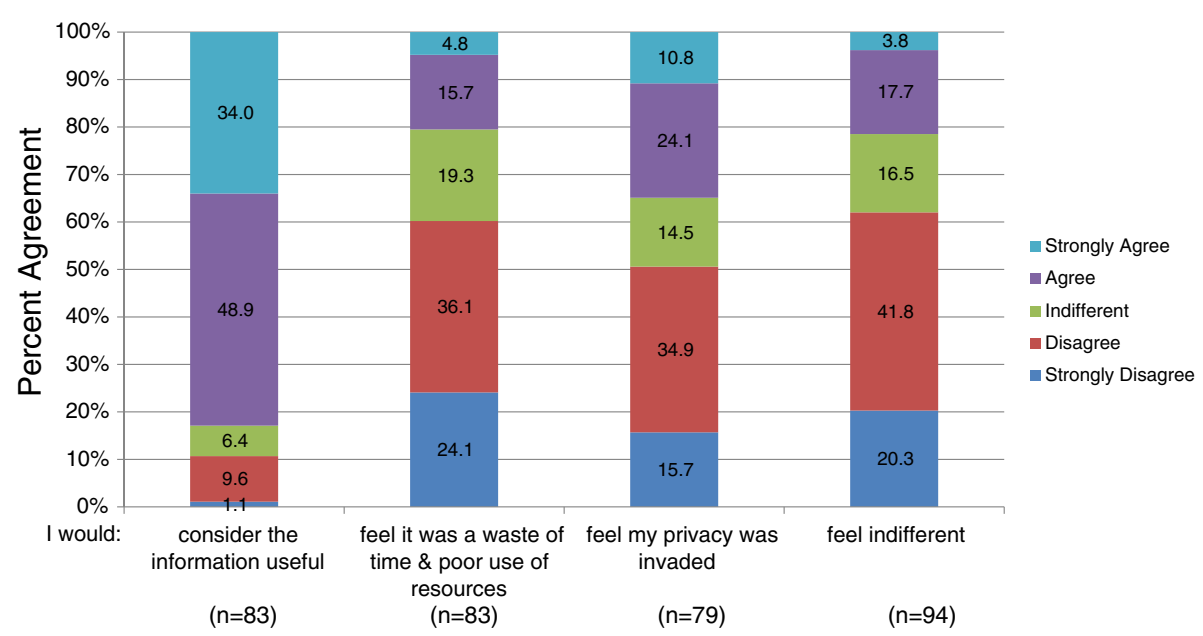

Figure 2 Patient perspectives on public health surveillance. Likert scale response of leukemia patients' perceptions on a factious scenario where a public healthcare worker identifies and notifies them about potential health risks. Question: How would you feel if a policy put a system in place that allowed this public healthcare worker to mail this information to you in order to warn you of your high risk health status? (a) I would consider the information useful. (b) I would feel it was a waste of time and poor use of resources of our public health care dollars. (c) I would feel my privacy was invaded. (d) I would feel indifferent. Due to rounding, totals may not equal $100 \%$. 


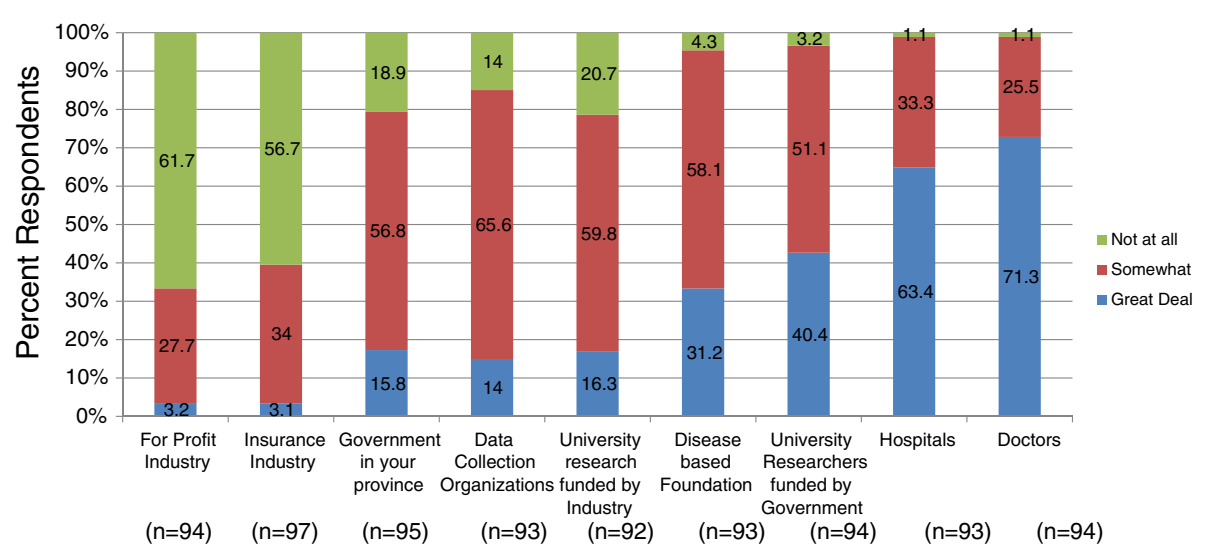

Figure 3 Patient perspectives on trust in actors and institutions involved in biobanking. Likert scale response of leukemia patients' perceptions on their level of trust for different individuals and organizations with the care and use of confidential health information. Question: How much do you trust the following individuals, organizations or groups with the care and use of your confidential health information? (a) For-profit industry, for example, a drug company. (b) Insurance industry. (c) Government in your province. (d) Data collection organizations (Stats Canada/Canadian Institute for Health Information). (e) University research funded by industry. (f) Disease based foundation (e.g., Kidney Foundation, Heart \& Stroke). (g) University researchers funded by government. (h) Hospitals. (i) Doctors. Due to rounding, totals may not equal $100 \%$.

Canadian Institute for Health Information $(65.6 \%)\left(x^{2}=\right.$ $52.966, \mathrm{df}=2, p<0.001)$, and industry-funded university research $(59.8 \%) \quad\left(x^{2}=32.719, \quad \mathrm{df}=2, \quad p<0.001\right)$ (Figure 3). Most patients had quite low levels of trust towards for-profit industry $(61.7 \%)\left(X^{2}=52.621, \mathrm{df}=2\right.$, $p<0.001)$ and the insurance industry $(56.7 \%)\left(x^{2}=\right.$ $44.923, \mathrm{df}=2, p<0.001)$. Of those patients who completed the follow-up survey, 16 participant responses changed such that there was even less trust towards for-profit industry $\left(\chi^{2}=27.856, \mathrm{df}=12, p=0.006\right)$, and 15 participants changed responses showing slightly less trust towards hospitals $\left(x^{2}=7.979, \mathrm{df}=3, p=0.046\right)$ (data not shown).

\section{Discussion}

Much public perception research on the ethical and legal aspects of research involving biobanks has been performed with patient populations, including adults and children, and healthy volunteers (e.g., general public, US veterans, and racial groups) in many jurisdictions. Yet little research has been conducted to specifically assess the perceptions of Canadian cancer patients. Surveying Canadian cancer patient perceptions provides an opportunity to compare these perceptions to those of different populations surveyed in other research studies. This work helps to provide a picture of the breadth of opinions relevant to the ethical and legal controversies associated with biobanking.

\section{Consent}

The topic of informed consent as it relates to biobanking has dominated public perception studies. A recent review shows that $51 \%$ of the 87 different empirical studies on biobanking discuss stakeholder perceptions on consent [23]. In our study, we limited our question to three consent types, despite the multitude of possible consent models for biobanking, so as to maintain simplicity in our questionnaire and because many of the ethical and legal issues for other variations of consent are similar [24]. Our results clearly showed that of the three options provided (re-consent, one-time consent, and tiered consent), the majority of patients (59.6\%) preferred a one-time consent. However, many preferred a form of consent that was more specific and ongoing in nature (e.g., some preferred to re-consent and nearly a third chose tiered consent). Our results corroborate findings from some studies done in other jurisdictions. One study analyzing consent preferences from breast cancer survivors in the Netherlands showed that $61 \%$ indicated that they would like to choose the type of future research, 56\% preferred a one-time general consent model, and $45 \%$ indicated that they would rather give permission for the current research, but not for other future research [25]. Another study examined the views on consent of African American and White American cancer patient groups who attended two healthcare facilities in Atlanta, Georgia. The researchers found that although the vast majority of patients from both cohorts were willing to participate (95\%), 57\% desired that researchers choose the type of future research using their samples while $10 \%$ wanted to choose using a checklist of options, and 33\% explained either option would be fine [26]. It is unknown why there are differences between different populations of cancer patients, but many factors could influence the difference in opinions including the ways in which the questions were posed in the surveys. 
Results of studies with the general population (who may or may not be patients) are in some respects comparable, but interesting differences are also present. In contrast to our study, a US nationwide study that offered participants different choices showed that $48 \%$ preferred blanket consent (consent for any future research), $42 \%$ preferred being asked at the initiation of each study, and 10\% preferred tiered consent [27]. In addition, a study conducted by our group surveying 1201 Albertans demonstrated that $51.8 \%$ preferred one-time consent, $30.2 \%$ chose tiered consent, and $18.0 \%$ preferred re-consent [22]. The slightly higher preference for a one-time consent by patients as compared to those in the general public may be due to their personal interest in the research and the high degree of trust in their medical team. In total, these results are similar to findings from our study and indicate that while the majority of participants are comfortable with a one-time consent, many prefer tiered consent or re-consent approaches indicating a desire for control.

We asked patients additional questions on re-consent and compared our results to a survey of 1201 Albertans [22], and a nationwide study of approximately 8735 Americans [27] (Table 4). Approximately $58 \%$ of patients and Albertans reported that re-consent was a waste of time and money compared to only $27 \%$ of Americans. Interestingly, 33.7\% of patients and 26\% of Americans thought it would be bothersome to reconsent in contrast to $51.9 \%$ of Albertans who felt this way. On other points, it seemed overall that cancer patient opinions from our survey on control, trust, or feeling respected and involved differed from the US general public and aligned more with the views of Albertans (Table 4). One possible explanation is that perhaps cancer patients, a group that has frequent interaction with the healthcare system, have a higher degree of trust in their physicians and researchers than the general public. Their situation may also mean that they view the relevant research as important and, as a result, feel less need to provide specific and ongoing consent.

\section{Withdrawal}

Very little public perception research covers the topic of withdrawing consent in the context of biobanking [23] and in many cases questions surrounding withdrawal are intimately tied to issues of privacy, consent, and trust. Most of the patients in our study (62.6\%) wanted to have the right to withdraw consent at any time. Our results found less support for unlimited withdrawal as compared to Albertans, where $71.2 \%$ indicated that participants should have a right to withdraw [22]. However, our results were similar to a Swedish study where $62 \%$ of participants reported feeling positive about the right to withdraw [28]. Yet there are studies that have found very different results. For example, an evaluation of 600 adult Egyptian patients found that only $28.8 \%$ believed in the right to withdraw their blood samples [29]. There is also evidence to suggest that some participants do not perceive a reason to withdraw, but feel it is an option that should be maintained in case others had concerns about the study [30]. Reasons for withdrawal could include a breach of security or scandal, negative news media about the research, changes to a participant's health status, burdensome requests from researchers, and negative responses from peers [31]. Most interesting was that compared to the initial survey results, more patients indicated that they should not have the right to withdraw in the follow-up survey. We speculate that this observation may be partially explained by the high degree of trust patients place in university-funded researchers and medical staff, and that they believe that biobanking research could advance medical treatments for leukemia.

The right to withdraw from research is supported by virtually all research ethics policies, but there are issues with the practicality of withdrawing consent as it relates to biobanking. Some are concerned that the right to withdraw consent for biobanking may be eroding because it could cause sample bias in a given population [32-34]. Yet withdrawing consent is a fundamental research ethics norm [35]. Overall, results from our study showed that patients reported they should have the right to withdraw consent at any time.

Table 4 A comparison of opinions on re-consenting for future biobanking research

\begin{tabular}{|c|c|c|c|c|c|c|}
\hline \multirow[b]{2}{*}{ I would feel: } & \multicolumn{2}{|c|}{ Patient survey (\%) } & \multicolumn{2}{|c|}{ US population (\%) } & \multicolumn{2}{|c|}{ Albertans (\%) } \\
\hline & $\begin{array}{c}\text { Agree-strongly } \\
\text { agree }\end{array}$ & $\begin{array}{c}\text { Disagree-strongly } \\
\text { disagree }\end{array}$ & $\begin{array}{c}\text { Agree-strongly } \\
\text { agree }\end{array}$ & $\begin{array}{c}\text { Disagree-strongly } \\
\text { disagree }\end{array}$ & $\begin{array}{c}\text { Agree-strongly } \\
\text { agree }\end{array}$ & $\begin{array}{c}\text { Disagree-strongly } \\
\text { disagree }\end{array}$ \\
\hline It was a waste of time \& money & 58.1 & 36.6 & 27 & 73 & 58.5 & 30.8 \\
\hline Bothered & 33.7 & 45.8 & 26 & 74 & 51.9 & 39.1 \\
\hline I have control & 36.9 & 28.5 & 75 & 25 & 51.0 & 32.5 \\
\hline More trust in the study & 39.5 & 26.7 & 75 & 25 & 48.1 & 34.8 \\
\hline Respected and involved & 51.7 & 18.4 & 81 & 19 & 56.7 & 26.5 \\
\hline
\end{tabular}

Due to rounding, totals may not equal $100 \%$. 
An additional complication in the context of banking samples from cancer patients is determining who has the authority to withdraw samples when there is no legal will or declaration of a proxy. This is especially important in the case of collecting and storing samples from cancer patients because patients could die soon after donation. Additional empirical research examining the complexities of the right to withdraw and the perceptions of different stakeholders is needed.

\section{Anonymity}

Patient preferences of whether samples are either deidentified or fully anonymized and cannot be traced back to the donor were roughly 50-50. Yet having samples fully anonymized becomes problematic when collecting and storing samples involving cancer patients because the diagnosis of samples is linked to the tailoring of treatment regimens for individual patients. It is unclear from our questionnaire whether patients understood this caveat when responding to the survey question.

\section{Return of results}

In general, research tells us that the general public and patients have a strong desire to receive individual results either for them or their descendants [23]. Our results confirm this trend. Indeed, about $98 \%$ of those surveyed wanted this information to be disclosed to themselves, their physicians, or both. This is, in fact, one of the few areas of almost universal agreement.

These results are similar to the perceptions of Albertans where $90 \%$ of participants wanted to be informed of research results in some way [22]. In general, many studies confirm that the public and patients have a strong preference to know research results [29,36-38]. However upon further examination of the types of research results participants desire, the numbers differ. Several studies indicate that many participants want to receive results in situations where treatment options are available and have a lower desire to know results for either untreatable conditions or where the significance of the finding is not well understood [39-41]. Our results clearly show that cancer patients have a high desire to know the results of research. Yet we reason that if patients were provided details on the different types of results that might be returned, their views are likely to be nuanced as we have seen in other studies.

\section{Ownership and decision making}

In the few surveys that capture perceptions on ownership, about $23-53 \%$ of participants report that the participant themselves are the owners of the samples $[25,41,42]$. Surprisingly, our survey results showed that only $19.4 \%$ of patients believed they were the owners and the majority (62.2\%) believed that research institutions owned the samples. The survey of Albertans also showed a relatively high number of participants (44.3\%) believed that the research institution owned samples, although a significant minority (25.7\%) of respondents believed they owned the samples [22]. We speculate that the high number of patients believing that the research institution owns the samples could be because they perceive government-funded researchers to be trustworthy and, therefore, feel comfortable with the research institution having an ownership-like interest. In addition, as we did not define the term "research institution," patients may conflate research institution with the hospital where they were treated (which, admittedly, is often the case). This explanation is supported by another study that observed that many patients responded that the hospital owned the samples [42]. Yet despite many patients believing that research institutions own samples, the majority of patients $(55.8 \%)$ indicated that they have the right to decide what is done with their samples. These findings are reinforced from a study showing that many participants prefer multiple data sharing options and want some control on decision-making [43]. More research is needed to better understand participant conceptions of ownership, the right to decide, and the factors that influence desires for control over their samples and health information.

\section{Trust}

Patients reported higher levels of trust in doctors, hospitals, and government-funded university researchers, moderate levels of trust in their provincial government, and low levels of trust in for-profit industry and insurance companies. Near identical results were also seen when surveying Albertans [22] and similar findings were seen in other public perception research $[44,45]$. Other than trusting actors in various organizations, there is some data suggesting that participants show less trust of biorepository research that has the potential to cause stigmatization or discrimination, or goes against deeply held cultural or religious beliefs, e.g., lineage determination, behavioral disorders, and inbreeding [5,10,20,36,44,45]. Although our survey questions did not discuss the different areas in which research samples may be used, in general, cancer patients have similar high levels of trust in the organizations as seen in other studies [22].

\section{Limitations}

The survey has several important limitations that merit discussion. It considers the opinions of leukemia patients from a specific geographical location, and opinions of cancer patients from other areas or other types of patients (i.e., surgical) may vary. To maintain anonymity, our survey did not gather information related to age, education, ethnicity, or religious background or belief 
system, and correlate this information with participant responses. One limitation specific to our survey was that some participants did not complete questions containing multiple parts (e.g., A through E) where each part required a single Likert scale response. We suspect that this may be due to misinterpreting the instructions which asked for a single response to each part, and this may bias responses as these were excluded from the analysis. As our survey was meant to capture broad patient perspectives and compare them with those of other Canadian stakeholders, we did not pose questions that attempted to determine the reasons behind participant responses. Future qualitative research with cancer patients would complement our survey and permit a richer understanding of reasons behind differing viewpoints.

\section{Conclusions}

Our survey results of Canadian cancer patients' perceptions on the ethical and legal issues of biobanking showed several interesting differences and similarities with the results of other surveys. Results on consent showed that many patients desire some form of control. As with most other studies, there seems to be general agreement that returning results of research and allowing participants to withdraw consent are desirable practices. It is interesting to note that as compared to the results of other surveys, more patients in our study felt that they should not have the right to withdraw consent. Although a statistically relevant association was not found, we speculate that because this patient population has a high degree of trust in their doctors, the hospital, and university-based researchers, they may not feel as strongly about a need for a right to withdraw. In addition, their belief in the importance of biobanking research for leukemia may also influence their views. Similarly, the high numbers of patients believing that the research institution owns their samples could also be explained, in part, by the elevated levels of trust they have for their clinical staff and researchers. Our study is one of a few that examines Canadian patient perceptions on biobanking and provides an important contribution to the broader understanding and public discourse surrounding biobanking, and thus has relevance for the development of research policy on biobanking.

\section{Additional file}

Additional file 1: Stakeholder survey: perspectives on biobanking

and tissue sampling. General population/patient population questionnaire.

\section{Competing interests}

The authors declare they have no competing interests.

\section{Authors' contributions}

All authors made substantial contributions to the conception and design of the research study, including drafting survey questions. ZM analyzed and interpreted the data, prepared tables and figures, and initially drafted the manuscript. JC disseminated the survey to participants, collected survey responses and critically revised the manuscript for important intellectual content. CR helped analyze and interpret the data, performed the statistical analysis, and revised the manuscript for important intellectual content. MM and JW helped analyze and interpret the data, and critically revised the manuscript for important intellectual content. TC helped write the initial draft of the manuscript, helped analyze and interpret the data, and critically revised the manuscript for important intellectual content. All authors have given final approval of the manuscript to be published.

\section{Acknowledgements}

This project would not be possible if it were not for the participants who took the time to complete the questionnaire(s) and we are most grateful for their time and efforts. We thank Drs. Mark Minden, Aaron Schimmer, Karen Yee, Andre Schuh, Vikas Gupta, and Joseph Brandwein for allowing us to recruit patients in their clinics at the Princess Margaret Hospital. This work was supported by the Cancer Stem Cell Consortium (CSCC) with funding from the Government of Canada through Genome Canada and the Ontario Genomics Institute (OGI-047); Allergy, Genes and Environment Network of Centres of Excellence Inc. (AllerGen); the Interdisciplinary Chronic Disease Collaboration funded by the Alberta Heritage Foundation for Medical Research (Alberta Innovates); and the Office of the Privacy Commissioner of Canada. We acknowledge the support of the cbcf Tumor Bank. We also like to thank Professor Amy Zarzeczny, Dr. Erin Nelson, Dr. Don Willison, Dr. Kathy Hudson, and the University of Alberta's Population Research Laboratory for their input in the design of the survey and approach. We are most appreciative for project support by Ms. Robyn Hyde-Lay. We would also like to thank the two reviewers for their insightful comments and feedback which have served to strengthen the manuscript.

\section{Author details}

${ }^{1}$ Alden March Bioethics Institute, Albany Medical College, 47 New Scotland Avenue, MC 153, Albany, NY 12208-3478, USA. ${ }^{2}$ Health Law and Science Policy Group, Rm 461 Law Centre, University of Alberta, 89 Avenue and 111 Street, Edmonton, AB T6G 2H5, Canada. ${ }^{3}$ Ontario Cancer Institute, Princess Margaret Hospital, University Health Network, 101 College Street, TMDT 3912, Toronto, ON M5G 1L7, Canada. ${ }^{4}$ Campbell Family Cancer Research Institute/Ontario Cancer Institute, University Health Network, Faculty of Medicine, University of Toronto, MaRS TMDT 8-363 101 College Street, Toronto, ON M5G 1L7, Canada. ${ }^{5}$ Princess Margaret Cancer Center, Campbell Family Cancer Research Institute/Ontario Cancer Institute, University Health Network, Faculty of Medicine, University of Toronto, 610 University Avenue, 9-113, Toronto, ON M5G 2M9, Canada. ${ }^{6}$ Health Law and Science Policy Group, Rm 462 Faculty of Law and School of Public Health, Law Centre, University of Alberta, 89 Avenue and 111 Street, Edmonton, AB T6G 2H5, Canada.

Received: 8 October 2012 Accepted: 28 February 2013

Published: 8 March 2013

\section{References}

1. Zika E, Paci D, Schulte in den Bäumen T, Braun A, RijKers-Defrasne S, Deschênes M, Fortier I, Laage-Hellman J, Scerri CA, Ibarreta D: Biobanks in Europe: Prospects for harmonisation and networking. Joint Research Centre, European Commission. [http://ftp.jrc.es/EURdoc/JRC57831.pdf].

2. The Cancer Human Biobank: [http://cahub.cancer.gov/].

3. BBMRI Biobanking and Biomolecular Resources Research Infrastructure: [http://www.bbmri.eu/index.php? option=com_content\&view=frontpage\&ltemid=27]

4. Statistics Canada. Biobank: [http://www.statcan.gc.ca/survey-enquete/ household-menages/5071u-eng.htm].

5. Master Z, Resnik DB: Incorporating exclusion clauses in informed consent for biobanking. Camb Q Healthc Ethics. in press.

6. Charo RA: Body of research - ownership and use of human tissue. New Engl J of Med 2006, 355:1517-1519.

7. Boggio A: Ownership of samples and data and territorial restrictions concerning data and samples beyond national boundaries. In Ethical 
Issues in Governing Biobanks. Global Perspectives. Chapter 11. Edited by Elger B, Biller-Andorno N, Mauron A, Capron AM. Farnham Surrey, England: Ashgate Publishing Limited; 2008:197-205.

8. Elger B: Withdrawal of consent and destruction of samples. In Ethical Issues in Governing Biobanks. Global Perspectives. Chapter 8. Edited by Elger B, Biller-Andorno N, Mauron A, Capron AM. Farnham Surrey, England: Ashgate Publishing Limited; 2008:131-165

9. Wolf SM, Lawrenz FP, Nelson CA, Kahn JP, Cho MK, Clayton EW, Fletcher JG, Georgieff MK, Hammerschmidt D, Hudson K, Illes J, Kapur V, Keane MA, Koenig BA, Leroy BS, McFarland EG, Paradise J, Parker LS, Terry SF, Van Ness $B$, Wilfond BS: Managing incidental findings in human subjects research: analysis and recommendations. J Law Med Ethics 2008, 36:219-248.

10. Mello MM, Wolf LE: The Havasupai Indian tribe case - lessons for research involving stored biologic samples. N Engl J Med 2010, 363:204-207.

11. Doerr A: Newborn bloodspot litigation: 70 days to destroy 5+ million samples. Genomics Law Report. [http://www.genomicslawreport.com/index.php/ 2010/02/02/newborn-blood-spot-litigation-70-days-to-destroy-5-millionsamples/]

12. Texas Civil Rights Project: Parents sue Texas health dept. and Texas A\&M over infant blood databank. [http://www.texascivilrightsproject.org/?p=1096].

13. Skloot R: The Immortal Life of Henrietta Lacks. New York: Crown Publishing; 2010.

14. Abbott A: Icelandic database shelved as court judges privacy in peril. Nature 2004, 429:118.

15. Gertz R: An analysis of the Icelandic Supreme Court judgement on the Health Sector Database Act. SCRIPT-ed 2004, 1:241-258.

16. Waxman J: Who owns my tissue? Drug Discovery and Development. [http:// www.dddmag.com/articles/2007/12/who-owns-my-tissue].

17. Godard B, Marshall J, Laberge C: Community engagement in genetic research: results of the first public consultation for the Quebec CARTaGENE Project. Comm Gen 2007, 10:147-158.

18. Doherty KC, Burgess MM: Engaging the public on biobanks: outcomes of the BC Biobank Deliveration. Pub Hith Gen 2009, 12:203-215.

19. Secko DM, Preto N, Niemeyer S, Burgess MM: Informed consent in biobank research: a deliberate approach to the debate. Soc Sci Med 2009, 68:781-789.

20. Godard B, Ozdemir V, Fortin M, Egalité N: Ethnocultural community leaders' views and perceptions on biobanks and population specific genomic research: a qualitative research study. Public Underst Sci 2010, 19:469-485.

21. McMurter B, Parker L, Fraser R, Magee JF, Kozancyzn C, Fernandez C: Parental views on tissue banking in pediatric oncology patients. Pediatr Blood Cancer 2011, 57:1217-1221.

22. Caulfield T, Rachul C, Nelson E: Biobanking, consent and control: a survey of Albertans on key research ethics issues. Biopreserv Biobank 2012, 10:433-438

23. Rachul C, McGuire A, Caulfield T: Public perceptions and biobanking: what does the research really say? Stud Ethics Law Technol 2012, 6:Article 3.

24. Master Z, Nelson E, Murdoch B, Caulfield T: Biobanks, consent and claims of consensus. Nat Methods 2012, 9:885-888

25. Vermuelen E, Schmidt MK, Aaronson NK, Kuenen M, van Leeuwen FE: Obtaining 'fresh' consent for genetic research with biological samples archived 10 years ago. Eur J Cancer 2009, 45:1168-1174.

26. Pentz RD, Billot $L$, Wendler D: Research on stored biological samples: views of African American and white American cancer patients. Am J Med Gen A 2006, 140:733-739.

27. Murphy J, Scott J, Kaufman D, Geller G, LeRoy L, Hudson K: Public perspectives on informed consent for biobanking. Am J Public Health 2009, 99:2128-2134.

28. Ring L, Lindblad ÅK: Public and patient perception of biobanks and informed consent. In Biobanks as Resources for Health. Edited by Hansson MG, Levin M. Uppsala, Sweden: Research Program Ethics in Biomedicine; 2003:197-206

29. Abou-Zeid A, Silverman H, Shehata M, Shams M, Elshabrawy M, Hifnawy T, Rahman SA, Galal B, Sleem H, Mikhail N, Moharram N: Collection, storage and use of blood samples for future research: views of Egyptian patients expressed in a cross-sectional survey. J Med Ethics 2010, 36:539-547.

30. Kaphingst KA, Janoff JM, Harris LN, Emmons KM: Views of female breast cancer patients who donated biologic samples regarding storage and use of samples for genetic research. Clin Genet 2006, 69:393-393.
31. Beskow LM, Dean E: Informed consent for biorepositories: assessing prospective participants' understanding and opinions. Cancer Epidemiol Biomarkers Prev 2008, 17:1440-1451.

32. Helgesson $G$, Johnsson $L$ : The right to withdraw consent to research on biobank samples. Med Health Care Philos 2005, 8:315-321.

33. Ye C, Giangregorio L, Holbrook A, Pullenayegum E, Goldsmith $\mathrm{CH}$, Thabane L: Data withdrawal in randomized controlled trials: Defining the problem and proposing solutions. Contemp Clin Trials 2011, 32:318-322.

34. Hug K, Hermerén $G$, Johansson M: Withdrawal from biobank research: Considerations and the way forward. Stem Cell Rev 2012. doi:10.1007/ s12015-012-9399-y.

35. Emanuel EJ, Wendler D, Grady C: What makes clinical research ethical? JAMA 2000, 283:2701-2711.

36. Fong $M$, Braun $\mathrm{KL}$, Chang RM: Native Hawaiian preferences for informed consent and disclosure of results from research using stored biological specimens. Pac Health Dialog 2004, 11:154-159.

37. Halverson CME, Ross LF: Engaging African-Americans about biobanks and the return of research results. J Community Genet 2012, 3:275-283.

38. Meulenkamp TM, Gevers SK, Bovenberg JA, Koppelman GH, van Hylckama Vlieg A, Smets EM: Communication of biobanks' research results: what do (potential) participants want? Am J Med Genet A 2010, 152A:2482-2492.

39. Hoeyer K, Olofsson BO, Mjörndal T, Lynöe N: Informed consent and biobanks: a population-based study of attitudes towards tissue donation for genetic research. Scand J Public Health 2004, 32:224-229.

40. Murphy J, Scott J, Kaufman D, Geller G, Hudson K: Public expectations for return of results from large-cohort genetic research. Am J Bioeth 2008, 8:36-43

41. Vermuelen E, Schmidt MK, Aaronson NK, Keunen M, van der Valk P, Sietses C, van den Tol P, van Leeuwen FE: Opt-out plus, the patients' choice: preferences of cancer patients concerning information and consent regimen for future research with biological samples archived in the context of treatment. J Clin Pathol 2009, 62:275-278.

42. Bryant RJ, Harrison RF, Start RD, Chetwood ASA, Chesshire AM, Reed MWR, Cross SS: Ownership and uses of human tissue: what are the opinions of surgical in-patients? J Clin Pathol 2008, 61:322-326.

43. McGuire AL, Hamilton JA, Lunstroth R, McCullough LB, Goldman A: DNA data sharing: research participants' perspectives. Genet Med 2008, 10:46-53.

44. Lemke AA, Wolf WA, Herbert-Beirne JH, Smith ME: Public and biobank participant attitudes toward genetic research participation and data sharing. Public Health Genomics 2010, 13:368-377.

45. Trinidad SB, Fullerton SM, Bares JM, Jarvik GP, Larson EB, Burke W: Genomic research and wide data sharing: views of prospective participants. Genet Med 2010, 12:486-495.

doi:10.1186/1755-8794-6-8

Cite this article as: Master et al:: Cancer patient perceptions on the ethical and legal issues related to biobanking. BMC Medical Genomics 2013 6:8

\section{Submit your next manuscript to BioMed Central and take full advantage of:}

- Convenient online submission

- Thorough peer review

- No space constraints or color figure charges

- Immediate publication on acceptance

- Inclusion in PubMed, CAS, Scopus and Google Scholar

- Research which is freely available for redistribution 